\title{
MONTEIRO LOBATO E A LITERATURA INFANTIL BRASILEIRA
}

\author{
Karina Juliete Moraes da Costa Matos ${ }^{1}$ \\ Jaelson do Carmo Cardoso Castro
}

\section{Resumo}

O presente trabalho tem como tema Monteiro Lobato e Literatura Infantil Brasileira, e tem como objetivo analisar a trajetória de Monteiro Lobato, e sua importância na Literatura Infantil Brasileira. A metodologia utilizada na pesquisa foi bibliográfica e documental, e através dela podemos destacar que Monteiro Lobato foi e continua sendo o maior escritor infantil brasileiro, com uma linguagem inovadora, trazendo aos textos um brasileirismo até então inédito para o gênero infantil. Através deste trabalho percebemos o interesse de Lobato em divulgar a cultura brasileira, e registrá-la em suas obras de maneira clara e objetiva, alcançando com elas as crianças brasileiras, fazendo com que elas pudessem se identificar com os personagens.

Palavras-chave: Literatura Infantil. Aprendizagem. Conhecimento. Educação.

\section{INTRODUÇÃO}

Sabemos que Monteiro Lobato teve grande importância para a Literatura Brasileira, mas destacaremos aqui seu trabalho na Literatura Infantil, cujos livros possuem características inéditas para a época, criando no meio literário um novo conceito. Mas, o que seria Literatura?

Literatura, segundo o Dicionário do Aurélio, possui cinco definições, que são: 1 Ciência do literato. 2 - Conjunto das obras literárias de um país ou de uma época. 3 - Escritos narrativos, históricos, críticos, de eloquência, de fantasia, de poesia, etc. 4 - Folheto que acompanha um medicamento ou alguns outros produtos, de conteúdo informativo sobre composição, administração, precauções, etc. 5 - Literatura de cordel: conjunto de folhetos literários populares, que os livreiros originalmente dependuravam em cordéis.

Originada do latim, a palavra Literatura é tida como a arte de escrever, no entanto, o termo Literatura Infantil surgiu no continente europeu. Os primeiros livros voltados ao público infantil surgiram a partir dos séculos XVII e XVIII, também na Europa.

\footnotetext{
1 Graduada em Letras-Língua Portuguesa pela Universidade Federal do Pará/UFPA. Pós-Graduanda em Metodologia do Ensino de Língua Portuguesa e Literatura pelo Centro Universitário Leonardo da Vinci/UNIASSELVI. E-mail: karinajulietematos@gmail.com.

2 Tutor do curso de pós-graduação do Centro Universitário Leonardo da Vinci/ UNIASSELVI. Mestre em Educação e Cultura pela Universidade Federal do Pará/ UFPA. E-mail: jaelsonc3@ hotmail.com.
} 
Até o ano de 1921 a Literatura Infantil Brasileira vivia de traduzir e publicar livros estrangeiros, sem uma identidade brasileira, apenas reprodução de publicações. A partir da publicação de Narizinho Arrebitado, de Monteiro Lobato temos um novo modelo, com características nacionais, no qual nossas crianças passam a se perceber, e se identificar, até mesmo como personagens das histórias. Um modelo nacionalista, com personagens brasileiros, características das nossas regiões nos cenários que ilustram as histórias.

No presente trabalho iremos investigar e analisar as principais características da Literatura de Monteiro Lobato e como ele se tornou um divisor de águas na Literatura Infantil. Buscaremos analisar a trajetória de Monteiro Lobato na Literatura, destacando sua importância na Literatura Infantil Brasileira. Também iremos:

- Traçar um histórico da Literatura Infantil Brasileira;

- Destacar os escritores de Literatura Infantil;

- Analisar as características da Literatura Infantil Brasileira antes e depois de Monteiro Lobato e

- Observar a intertextualidade presente no livro Narizinho Arrebitado.

Através da análise dos personagens e do Sítio do Picapau Amarelo buscaremos, neles, influências de Jean Piaget e Lev Vygotsky na construção das características de cada um destes personagens e do próprio ambiente em que se passam as histórias. Será analisado também como Monteiro Lobato continua presente no imaginário infantil brasileiro até os dias de hoje.

\section{O SURGIMENTO DA LITERATURA INFANTIL}

Até meados dos séculos XV a XVII não havia infância. Crianças e adolescentes eram considerados adultos em miniatura, assumiam responsabilidades desde muito cedo e tinham que se comportar de fato como adultos. Não haviam cuidados específicos para elas nem se era exigido dos seus cuidadores preparação alguma.

\footnotetext{
Não se tem notícia de camponeses ou artesãos registrando suas histórias de vida durante a Idade média, e mesmo os relatos dos nobres de nascimento ou dos devotos não costumavam demonstrar muito interesse pelos primeiros anos de vida (...). De forma semelhante, durante o período moderno na Inglaterra, as crianças estiveram bastante ausentes na literatura, fossem o drama elizabetano ou os grandes romances do século XVIII. A criança era, no máximo, uma figura marginal em um mundo adulto. (HEYWOOD, 2004, p.10)
}

As crianças não eram registradas nas artes, fossem elas quais fossem, eram quase que esquecidas, marginalizadas, era quase como se não houvesse espaço ou lugar para elas no mundo, apenas os adultos mereciam destaque e representação em toda a sociedade. 
Quando se começou a falar de infância, das necessidades que elas possuem, de como precisam ser ensinadas, passou a haver uma preocupação em criar materiais apropriados para as crianças. Era preciso haver maneiras de educá-las, elas precisavam aprender como se tornarem adultas, deixariam de ser uma página em branco para se tornar seres pensantes.

A Literatura Infantil tem seu início nas narrativas orais entre os séculos IX e X, sendo repassadas dessa forma por gerações. Por volta dos séculos XVII e XVIII, surgiram na Europa os primeiros livros infantis e com isso temos os primeiros nomes da Literatura Infantil: Charles Perrault, Irmãos Grimm, Cristin Anderson, Lewis Carrol, Collodi, Frent Baum.

Os primeiros escritores de Literatura Infantil inicialmente coletaram as narrativas orais que circulavam entre o povo, registrando-as e publicando-as.

As narrativas infantis conhecidas atualmente como Clássicos da Literatura Infantil não foram escritas tal como as conhecemos hoje, possuíam um caráter mais violento, representando muito da sociedade da época em que foram escritas.

\footnotetext{
Cavaleiros andantes, reis, rainhas, princesas e príncipes bons e maus, fadas, bruxas, metamorfoses de criaturas humanas em animais (ou vice-versa), ogres e ogressas canibalescos, maldições, profecias, madrastas, crianças abandonadas, crianças que são entregues a alguém para serem mortas, fantasmas e magos, gênios benfazejos e malfazejos... é a fantástica legião de personagens que a partir do século XVII os escritores cultos vão descobrir na tradição oral dos povos europeus e criar a Literatura Infantil que hoje conhecemos como "tradicional" [...] (COELHO, 1991, p. 66).
}

Com o passar do tempo, a medida que as narrativas orais iam sendo retransmitidas, algumas características foram desaparecendo, entre elas: a violência, o canibalismo, entre outros. Certamente que houveram adaptações para que os textos escritos pudessem agradar ao público infantil, permanecendo em grande maioria apenas os elementos fantásticos que pudessem agradar as crianças.

Charles Perrault, Irmãos Grimm, Cristin Anderson são alguns dos escritores que ao coletar as narrativas orais e as publicar deram início ao que hoje conhecemos como Literatura Infantil.

\subsection{O SURGIMENTO DA LITERATURA INFANTIL NO BRASIL}

Enquanto na Europa surgia a Literatura Infantil, no Brasil pouco havia sido construído ainda na Literatura. Até o século XIX não havia aqui escritor para o público infantil. O que era produzido era fruto de traduções de livros estrangeiros. E mesmo as traduções eram escassas.

[...] a tradução de As aventuras pasmosas do Barão de Munkausen e, em 1818, a coletânea de José Saturnino da Costa Pereira, Leitura para meninos, contendo uma coleção de histórias morais relativas aos defeitos ordinários às idades tenras, e um 
diálogo sobre geografia, cronologia, história de Portugal e história natural. Mas essas publicações eram esporádicas (a obra que se seguiu a elas só surgiu em 1848, outra edição das Aventuras do Barão de Münchhausen, agora com a chancela da Laemmert) e, portanto, insuficientes para caracterizar uma produção literária brasileira regular para a infância. (LAJOLO e ZILBERMAN, 2010, p. 23-24).

No Brasil, o surgimento dessa modalidade só inicia realmente em 1921 com a publicação de Narizinho Arrebitado, de Monteiro Lobato. Nesse livro teremos uma literatura infantil brasileira, com características próprias, não mais cópias e reproduções de modelos externos.

No livro “Literatura Infantil - Teoria e Prática” (2003), Maria Antonieta Antunes Cunha afirma que:

Com Monteiro Lobato é que tem início a verdadeira literatura infantil brasileira. Com uma obra diversificada quanto a gêneros e orientação, cria esse autor uma literatura centralizada em algumas personagens, que percorrem e unificam seu universo ficcional. No Sítio do Pica-Pau Amarelo vivem Dona Benta e Tia Nastácia, as personagens adultas que "orientam" crianças (Pedrinho e Narizinho), "outras criaturas" (Emília e Visconde de Sabugosa) e animais como Quindim e Rabicó. (CUNHA, 2003, p. 24).

Temos em Lobato um nome a ser lembrado como criador da Literatura Infantil Brasileira. Personagens originais, não inspirados nos contos estrangeiros, e trazendo em suas narrativas situações comuns das crianças brasileiras. Segundo Cademartori:

A literatura infantil brasileira inicia sob a égide de um dos nossos mais destacados intelectuais: Monteiro Lobato. Se isso, por um lado, prestigiou o gênero no seu surgimento, por outro, fez com que, após Lobato, por muito tempo, a literatura infantil brasileira vivesse à sombra de seu nome. (1987, p. 43).

A partir das obras dele temos uma revolução na produção literária voltada ao público infantil no Brasil. Lobato inovou e abriu caminho para que mais escritores trilhassem seus caminhos. E sendo referência ao longo de muito tempo, diversos autores permaneceram à sua "sombra".

A partir de 1930 surgem novos nomes da Literatura Infantil Brasileira, como Cecília Meirelles, Viriato Correia e outros. Esses autores traziam consigo a preocupação de destacar e valorizar aspectos nacionais, como o folclore e a cultura, algumas das características do Modernismo.

Entre 1940 e 1950 alguns escritores de renome começam a se interessar em escrever para crianças, entre eles temos Mário Quintana, Vinicius de Moraes e Clarice Lispector. 
Na década de 70 há uma explosão de produção literária voltada ao público infantil, nesse período se destacam: Ana Maria Machado, Ruth Rocha, Fernanda Lopes de Almeida, e muitos outros autores.

A partir de 1980 temos Lygia Bojunga Nunes e Roger Melo, que muito se destacam na produção infantil.

\subsection{QUEM FOI MONTEIRO LOBATO?}

Monteiro Lobato (1882-1948) foi um escritor e editor brasileiro. Tendo como obra principal O Sítio do Pica-pau Amarelo", ganhou grande destaque na literatura infantil. Criou a "Editora Monteiro Lobato" e mais tarde a "Companhia Editora Nacional".

Reconhecido por ser um dos primeiros autores de literatura infantil de nosso país e de toda América Latina. Grande parte de suas obras é composta por Literatura Infantil e seu trabalho possui caráter nacionalista.

Segundo Silva:

Monteiro Lobato tinha a convicção de que a Literatura Infantil deveria reunir divertimento e informação, pois acreditava que, para a criança, aprender também dá prazer. Como não confiava na eficácia da escola, tratou de preencher com as aventuras do Sítio as lacunas que o ensino formal deixava em aberto. (SILVA, 2009, p. 28).

Diante disso, podemos perceber que seus livros traziam informações que poderiam ser estudadas na escola, mas que muitas vezes não eram. Sua obra era também educadora. A Literatura escrita por ele tinha a função também de ensinar, mas de forma diferente da que era utilizada nas escolas.

Seus livros infantis foram publicados conforme a sequência a seguir: 1920 - A menina do Narizinho Arrebitado, 1921 - Fábulas de Narizinho, 1921 - Narizinho arrebitado, 1921 - O Saci, 1922 - O marquês de Rabicó, 1922 - Fábulas , 1924 - A caçada da onça, 1924 - Jeca Tatuzinho, 1924 - O noivado de Narizinho, 1927 - As aventuras de Hans Staden, 1928 - Aventuras do príncipe, 1928 - O Gato Félix, 1928 - A cara de coruja, 1929 - O irmão de Pinóquio, 1929 - O circo de escavalinho, 1930 - Peter Pan, 1930 - A pena de papagaio, 1931 - Reinações de Narizinho, 1931 - O pó de pirlimpimpim, 1932 - Viagem ao céu, 1933 - Caçadas de Pedrinho, 1933 - Novas, Reinações de Narizinho, 1933 - História do mundo para as crianças, 1934 - Emília no país da gramática, 1935 - Aritmética da Emília, 1935 Geografia de Dona Benta, 1935 - História das invenções, 1936 - Dom Quixote das crianças, 1936 - Memórias da Emília, 1937 - Serões de Dona Benta, 1937 - O poço do Visconde , 1937 
- Histórias de Tia Nastácia, 1938 - O museu da Emília, 1939 - O Pica-Pau Amarelo, 1939 - O Minotauro, 1941 - A reforma da natureza, 1942 - A chave do tamanho, 1944 - Os doze trabalhos de Hércules, 1947 - Histórias diversas.

\subsection{CARACTERÍSTICAS DA ESCRITA DE MONTEIRO LOBATO}

Como escritor inovador, suas obras traziam características até então não utilizadas. Incomparável com qualquer escritor brasileiro de sua época, tornou -se o principal representante da Literatura Infantil Brasileira, conforme afirma Coelho, 1982: "Monteiro Lobato permaneceu como o principal representante da literatura infantil brasileira durante os anos 30 e $40 \%$.

Sendo ainda em nossos dias uma referência na Literatura Infantil Brasileira, Lobato permanece como um grande e inovador escritor, trazendo para o gênero infantil suas ideias através dos livros. Falar do campo, do interior brasileiro, das peculiaridades nacionais sem dúvida foram de extrema importância para cativar as crianças de um Brasil ainda bastante rural. Num cenário em que quase não havia livros infantis, Lobato encheu de leitura as crianças tanto de sua época quanto posteriores a ela.

Carvalho (1983) coloca Monteiro Lobato como "o maior clássico da Literatura Infantil Brasileira”.

As crianças descobriram nos livros de Lobato uma nova realidade que lhes permitia viajar em vários mundos com a magia do pó de pirlimpimpim. Imaginar um sítio em que tudo é possível com toda certeza fascinou-as.

Os maiores clássicos sem dúvida estão representados nos livros dele, que soube incluir em suas próprias histórias os demais clássicos da Literatura Internacional, criando uma intertextualidade incrível, um diálogo com as obras primeiras da Literatura Infantil, da mitologia, das lendas nacionais, e mais uma infinidade de temas, fazendo com que sua obra seja considerada completa.

Ao contrário dos clássicos estrangeiros, ele não recriou seus contos de outros; ele os criou. Embora se utilizasse do rico acervo maravilhoso da Literatura Clássica Infantil de todo o mundo, a inspiração maior e básica de Lobato foi a própria criança, os motivos e os ingredientes de sua vivência: suas fantasias, suas aventuras, seus objetos de jogos e brinquedos, suas travessuras e tudo o que povoa a sua imaginação... Reencontrou a criança, amealhou toda a riqueza e criatividade de seu mundo maravilhoso e construiu um universo para ela, num cenário natural, enriquecido pelo Folclore de seu povo, aspecto indispensável à obra infantil. (CARVALHO, 1983, p. 133). 
Utilizou com maestria diversos livros dentro de seus próprios livros, usando sempre referências literárias reconhecidas internacionalmente, sem deixar de trabalhar seu próprio tema em cada livro. Falou de assuntos pouco abordados por outros autores, tais como Geografia, matemática, ensinou sobre planetas, falou de coisas já sabidas, e de coisas que ainda não se sabia ao certo, como sobre o Petróleo no Brasil, ainda não descoberto na época.

Com uma linguagem bem brasileira, seus textos não traziam as características de muitos de seus antecessores, que escreviam para crianças com o intuito de ensinar valores morais, sem objetivo de fazer de seus textos prazerosos para a leitura.

[...] o texto apresenta uma feição bastante distinta daquela que marca a narrativa didática e moralizante. $\mathrm{O}$ principal traço de diferenciação consiste em que a história de Monteiro Lobato procura interessar a criança, captar sua atenção e diverti-la. É bastante conhecido o seu ideal de livro: um lugar onde a criança possa morar. Para alcançá-lo, o autor reconhecia a necessidade do gênero sofrer modificações e expressa essa intenção já na sua primeira obra. (ZILBERMAN e MAGALHÃES, 1987, p. 135 $-136)$.

Para ZILBERMAN e MAGALHÃES Lobato trouxe em seus textos o objetivo de envolver a criança na leitura, fazer com que ela de fato se interessasse pelo livro. Não é leitura por obrigação, é ler por querer de verdade, pra sanar curiosidades, sentir alegria ao chegar no final do livro.

Segundo Coelho,

[...] eles se sentiam identificados com as situações narradas; sentiam-se à vontade dentro de uma situação familiar e afetiva, que era subitamente penetrada pelo maravilhoso ou pelo mágico, com a mais absoluta naturalidade. Tal como Lewis Carroll fizera com Alice no País das Maravilhas, na Inglaterra de cinquenta anos antes, Monteiro Lobato o fazia no Brasil dos anos 20: fundia o Real e o Maravilhoso em uma única realidade. (COELHO, 1991, p. 227).

Essa representatividade da criança brasileira foi fundamental para que as crianças se interessassem pelos livros e suas histórias. Não somente a representatividade brasileira, como a intertextualidade, a conversa das histórias de Lobato com histórias clássicas da Literatura Infantil. Um misto de personagens novos e já conhecidos do público.

[...] é o sítio do Picapau Amarelo, propriedade de Dona Benta, que vive originalmente acompanhada de sua neta, a menina Lúcia, conhecida por Narizinho, e de uma cozinheira antiga e fiel, Tia Nastácia. Trata-se de uma população pequena para preencher um cenário tão grande, mas as personagens multiplicam-se rapidamente, com a inclusão de outros seres humanos (Pedrinho), seres mágicos (os bonecos animados Emília e Visconde), animais falantes (o porco Rabicó, o burro Conselheiro e o rinoceronte Quindim), sem falar dos eventuais seres aquáticos, habitantes do Reino das Águas Claras, localizado nas cercanias do sítio, ou dos visitantes mais ou menos habituais, como Peninha, o Gato Félix ou o Pequeno Polegar. (LAJOLO e ZILBERMAN, 2010, p. 55). 
Essa riqueza de personagens já existentes com os recém-criados moradores do Sítio, já no primeiro livro, sem dúvida, encantou os leitores.

Cademartori (1987) afirma que:

O revolucionário na obra de Lobato ganha maior abrangência na literatura infantil que ele inaugura entre nós. Rompendo com os padrões prefixados do gênero, seus livros infantis criam um mundo que não se constitui num reflexo do real, mas na antecipação de uma realidade que supera os conceitos e os preconceitos de uma situação histórica em que é produzida. O esforço de compreensão crítica do passado permite, em suas histórias, um redimensionamento do presente que, por sua vez, torna possível a prospecção, ou seja, o olhar para o futuro. (1987, p. 48 e 50).

Trazer de uma forma tão natural entre seus próprios personagens essa mistura com os clássicos infantis foi uma inovação excepcional. O rompimento com as práticas anteriores de apenas copiar o que vinha de fora e criar uma literatura nova para as crianças brasileiras fez com que Lobato se destacasse entre os demais escritores de sua época, e ao mesmo tempo fez com que eles tivessem nele uma inspiração para suas próprias criações. Cademartori (1987) ainda diz que:

\begin{abstract}
Monteiro Lobato cria, entre nós, uma estética da literatura infantil, sua obra constituindo-se no grande padrão do texto literário destinado à criança. Sua obra estimula o leitor a ver a realidade através de conceitos próprios. Apresenta uma interpretação da realidade nacional nos seus aspectos social, político, econômico, cultural, mas deixa sempre espaço para a interlocução com o destinatário. (CADEMARTORI, 1987, p. 51).
\end{abstract}

Retratado hoje como o criador de uma Literatura Infantil genuinamente Brasileira, Lobato ainda hoje encanta crianças, jovens, adultos, e tantos quantos se dispuserem a ler e conhecer suas obras. Elas refletem a realidade brasileira da época, os conflitos, as peculiaridades do país, a política, dessa forma, seus livros marcaram a trajetória da Literatura Brasileira.

Segundo Coelho (1995):

Foi em pleno período de confronto entre tradicional (formas já desgastadas do Romantismo? Realismo) e o moderno (representado pelo modernismo de 22) e Monteiro Lobato inicia a invenção literária que cria o verdadeiro espaço da literatura infantil no Brasil. (p.57).

Segundo ele, de certa forma Lobato inventou a Literatura Infantil Brasileira, deu início, e abriu caminho para que mais escritores seguissem por ele. 


\title{
2.4 ANALISANDO O LIVRO NARIZINHO ARREBITADO
}

Narizinho Arrebitado foi a primeira obra de uma sequência de livros que contam as aventuras da turma do Sítio do Picapau Amarelo. Por ser o primeiro de seus livros voltado para o público infantil, faz-se necessário um olhar sobre ele, para que possamos entender os objetivos de Monteiro Lobato ao escrevê-lo.

A riqueza das histórias e dos personagens sem dúvida trazem uma grande quantidade de elementos que iremos analisar.

A descrição do local com árvores tipicamente brasileiras: o sítio é banhado por um ribeirão, possui um pomar com ingazeiros e jabuticabeiras no terreiro:

\begin{abstract}
Além da boneca, o outro encanto da menina é o ribeirão que passa pelos fundos do pomar. Suas águas, muito apressadinhas e mexeriqueiras, correm por entre pedras negras de limo, que Lúcia chama as "tias Nastácias do rio”.(...) Todas as tardes Lúcia toma a boneca e vai passear à beira d'água, onde se senta na raiz dum velho ingazeiro para dar farelo de pão aos lambaris. (LOBATO, 1920 p. 2-3)
\end{abstract}

A descrição do lugar como um sítio natural, cheio de plantações e banhado por um rio foi sem dúvidas um dos fatores que cativou as crianças. Quem das crianças não queria morar num local onde pudesse sempre banhar-se no rio e comer frutas diretamente no "pé da árvore"? Ou ainda subir nos galhos das plantas e fazer estripulias pelo terreiro?

Sonho e fantasia se misturam com a realidade de maneira surpreendente, que inclusive os adultos participam da fantasia das crianças. Os adultos não duvidam das histórias das crianças e ainda participam delas, o que mostra uma compreensão enorme para com elas. Todos conversam com a boneca falante, embora com espanto, conforme mostra trecho do livro:

Dona Benta era outra que achava muita graça nas maluquices da boneca. Todas as noites punha-a ao colo para lhe contar histórias. Porque não havia no mundo quem gostasse mais de história do que a boneca. (LOBATO, 1920 P. 21)

A intertextualidade ora implícita ora explícita no livro com a presença de Dona Carochinha, Pequeno Polegar, Bela Adormecida, Aladin, Gato de Botas, Marques de Carabás, Gato Félix, Branca de Neve, Pinóquio, já na página 7. Personagens de contos populares já conhecidos no Brasil, ainda que fossem de autores estrangeiros, passeavam livremente nas histórias e aventuras do sítio. O livro Contos da Carochinha publicado em 1983 no Brasil por Alberto Figueiredo Pimentel, traduziu e adaptou contos populares para o Brasil tornou conhecidos os personagens, que agora passeiam pelas histórias de Monteiro Lobato. 
De maneira brilhante, Lobato conseguiu incluir em seus livros o ensino de conteúdos escolares, oferecendo para as crianças uma série de informações úteis, e conteúdos que deveriam ser vistos nas escolas.

Utilizou-se de diversos recursos linguísticos na construção dos textos, de maneira que as histórias foram descritas com riqueza de detalhes. De acordo com Naná Pinheiro em seu blog Charadas no escuro:

\begin{abstract}
Lobato inova em todos os aspectos em seu projeto literário infantil. No que tange aos aspectos narrativos temos alguns recursos estilísticos, tais como: a abundância de adjetivos, usados em sua maioria para ampliar a descrição as personagens e espaços geográficos; a repetição de verbos que dão maior ênfase à ação; uso de uma linguagem mais coloquial visando romper a barreira entre o oral e o escrito e, desse modo, aproximando o leitor; bem como o uso do discurso direto e indireto livre. O discurso lúdico talvez seja um dos traços mais significativos que colocam Lobato na posição de idealizador e construtor de uma nova forma de literatura infantil. (2013, p. 1)
\end{abstract}

Segundo Naná a inovação de Lobato ocorre tanto na criatividade quanto na própria linguagem utilizada por ele, com recursos linguísticos e estilísticos.

Outro recurso interessante é a menção ao Barão de Münchhausen, cujas histórias fantásticas são muito exageradas.

Karl Friedrich Hieronymus von Münchhausen (11 de maio de 1720-22 de fevereiro de 1797) o Barão de Münchhausen, foi um conhecido militar alemão cujas histórias serviram de base para uma série chamada As Aventuras do Barão de Münchhausen.

A referência nos faz perceber uma metáfora das aventuras da turma do sítio com as do referido Barão, cujas histórias absurdas não tinham explicação alguma, da mesma forma que no Sítio do Picapau Amarelo muita coisa não se explicava e tudo podia acontecer, inclusive uma boneca podia falar.

\title{
2.4 OS PERSONAGENS DO SÍTIO DO PICAPAU AMARELO E O QUE ELES REPRESENTAM
}

Cada personagem principal do Sítio do Picapau Amarelo tem suas características, exercem um papel nas histórias. Observamos que eles representam determinados elementos dentro da educação e do processo de aprendizagem. Percebemos que Lobato desenhou nos livros uma simbologia, fazendo com que muitos nem mesmo percebessem os papéis dos personagens, mas cada um foi criado com um objetivo específico, a ser desenvolvido, objetivo que foi alcançado com êxito por cada um deles. Destacaremos aqui algumas dessas características e simbologias. 
Tia Anastácia: "tia Nastácia, negra de estimação que carregou Lúcia em pequena" inicialmente apresentada dessa forma, vemos na personagem uma sabedoria empírica e uma crença cristã. Ela durante as histórias, além de ser uma excelente cozinheira, traz consigo conhecimentos adquiridos no decorrer de sua vida, e os repassa naturalmente sempre que necessário.

Tia Anastácia, essa é a ignorância em pessoa. Isto é ignorante propriamente, não. Ciência e mais coisas dos livros, isso ela ignora completamente. Mas nas coisas práticas da vida é uma verdadeira sábia. (LOBATO, 1972, p. 98).

Conforme observamos, não possui conhecimento científico, mas conhecimento de mundo, e conhecimento de vida, adquirido através do senso comum e da observação. Temos nela o que seria o conhecimento vulgar, portanto vemos em tia Nastácia a simbologia do empirismo.

Dona Benta: Ao contrário de tia Anastácia, Dona Benta possui muito conhecimento adquirido através dos livros que lê, é uma grande contadora de histórias. Representa aqui o professor, o erudito que possui o conhecimento, e também a habilidade de o ensinar a quem quer que seja, mas sempre busca por mais. Seu aprendizado é uma busca constante.

O que mais gosto nela é o seu modo de ensinar, de explicar qualquer coisa. Fica tudo claro como água. E como sabe coisas a diaba! De tanto ver aqueles livros lá do quarto, ficou que até brincando bateu o Visconde em ciência. (LOBATO, 1972, p. 98).

Se Dona Benta é o conhecimento adquirido pelos livros, e Tia Anastácia o conhecimento empírico, Lobato construíra nos livros o ambiente perfeito para o ensinar ambos, cada um de uma forma, mas ao final, a criança saberia os identificar.

Visconde de Sabugosa: O Visconde nos apresenta um mundo científico, matemático. Temos nele o sábio, o cientista, que questiona o conhecimento empírico. Seu conhecimento é baseado nos livros que "devora". Representa os intelectuais ou, como conhecemos hoje, os nerds.

O Visconde havia encontrado uma trigonometria velha, que pertencera ao cônego Encerrabodes..., tamanha foi sua satisfação que arrancou o livro dali e saiu de braço dado com ele para um passeio pelos corredores. E por lá ficaram até o dia seguinte, a conversar sobre "senos" e cosenos. ( LOBATO, 1971, p. 220).

A representatividade dos intelectuais nos faz perceber que Lobato busca inserir nas histórias os diversos perfis a fim de que as crianças possam se identificar com os personagens. 
Enquanto alguns buscam aventuras, e com elas adquirem conhecimentos, outros buscam primeiramente os conhecimentos, mas também são incluídos nas aventuras.

Emília: A boneca de pano que ganha vida na história, representa as crianças menores, que possuem uma visão de mundo diferente dos adultos. Uma boneca muito falante que se punha a falar coisas sem sentido, com uma forma de pensar inusitada. Apreciadora de histórias contadas por Dona Benta, também nos mostra a imaginação fértil dos pequenos.

\footnotetext{
Viu que a fala da Emília ainda não estava bem ajustada, coisa que só o tempo poderia conseguir. Viu também que era de gênio teimoso e asneirenta por natureza, pensando a respeito de tudo de um modo especial todo seu. - Melhor que seja assim, filosofou Narizinho. - As ideias de vovó e tia Nastácia a respeito de tudo são tão sabidas que a gente já as adivinha antes que elas abram a boca. As ideias de Emília hão de ser sempre novidades. (LOBATO, 1920, p. 18)
}

De acordo com Jean Piaget, Emília representaria a criança no estágio Pré-Operatório, onde há uma preparação e organização das operações concretas. Emília vive num mundo de imaginação, e ao voltar-se para a realidade surge o aparecimento da linguagem, ainda que através de uma pílula falante.

Pedrinho: Sem muitas informações iniciais no primeiro livro da saga, percebemos que Pedrinho é um garoto da cidade, neto de Dona Benta, corajoso aventureiro e curioso. Aparentemente incluído no livro para que não parecesse que era feito apenas para meninas. Lobato buscou em suas histórias fazer com que cada leitor conseguisse se imaginar como sendo um dos personagens por isso a introdução de um personagem do sexo masculino foi fundamental para que seu objetivo fosse alcançado.

Narizinho: Narizinho tem sete anos, é morena como jambo, gosta muito de pipoca e já sabe fazer uns bolinhos de polvilho bem gostosos.

Pedrinho e Narizinho são as crianças que buscam o aprendizado a cada nova aventura. Sempre aparecem mediados pelos adultos, a saber Dona Benta, Tia Anastácia e Visconde. Simbolizam os alunos, e os conhecimentos que adquirem no decorrer da vida familiar e também escolar. A mistura de formas de aprendizado enriquece o conhecimento deles. Aprendem brincando, experimentando e vivendo suas aventuras.

Para Piaget (1971) elas estariam no Estágio operacional concreto que vai de 7 a 11 anos, onde a criança inicia o pensamento lógico, e desenvolve a habilidade de resolver problemas pequenos mentalmente.

Interessante mencionar que ao mesmo tempo que podemos fazer análise dos personagens através das teorias de Jean Piaget, podemos também relacioná-los as teorias de Vygotsky, que afirmava que o conhecimento é adquirido através das relações sociais, e pode ser mediado. Como mediadores temos então Dona Benta, Tia Anastácia e o Visconde de 
Sabugosa, que interagem e participam ativamente das aventuras e de toda a construção do conhecimento.

Para Vygotsky (1989) o aprendizado ocorre através das relações sociais, sendo sempre mediado por algo ou alguém e o ambiente externo influencia muito nesse processo de aquisição de conhecimentos. O Sítio do Picapau Amarelo tem um importante papel dentro do processo de ensino, pois nele as crianças encontraram o ambiente perfeito para aprender através dos personagens.

Percebemos dessa forma que Monteiro Lobato trouxe através de cada personagem um elemento para ensinar as crianças. Seu objetivo não era apenas entreter os leitores, mas contribuir com o aprendizado deles.

\subsection{COMO A OBRA DE MONTEIRO LOBATO FOI IMORTALIZADA E SOBREVIVE ATÉ OS DIAS ATUAIS?}

A Literatura contribui com a sociedade, trazendo em si registros de todas as épocas, sejam eles reais ou ficção. Imortalizado na Literatura Infantil Brasileira através da publicação de seus livros, eles atravessam gerações e alcançam crianças até nossos dias. A imaginação da criança é envolvida pelo que lê, e isso fascina, desde as primeiras publicações até as últimas.

A Literatura tem um papel histórico, retratando costumes e culturas de diferentes povos. De maneira brilhante, Lobato conseguiu representar através de seus personagens figuras brasileiras. A forma como ele deu vida aos personagens trazendo o sentimento de pertencimento da criança em relação ao sítio, e a cada aventura vivida por eles ajudou a encantar tanto as crianças quanto os adultos que tiveram contato com as obras.

Se Lobato conseguiu com seu primeiro livro mexer com o imaginário infantil, mais ainda o faz no presente, onde as crianças têm acesso as mais diferentes formas de comunicação. Ao ser adaptado para a televisão em 1952 pela TV Tupi, com sua primeira transmissão em 3 de junho do referido ano, ficando no ar até 6 de março de 1963, com um total de doze temporadas e 360 episódios de 25 a 30 minutos cada episódio, a adaptação para a tv foi um fator que ajudou a impulsionar ainda mais os personagens do Sítio, alcançando mais crianças.

Dessa forma Lobato continua sendo apresentado para as crianças, seja através dos livros, seja através da Tv, ou de outras plataformas de comunicação, que fazem com que o Sítio do Picapau Amarelo continue no imaginário de adultos e crianças brasileiros. 


\section{CONSIDERAÇÕES FINAIS}

Monteiro Lobato deu início ao que conhecemos hoje como Literatura Infantil Brasileira, trazendo em seu primeiro livro personagens que caíram no gosto das crianças e até mesmo de adultos. Percebemos que cada personagem representa um papel dentro da educação, e da construção do aprendizado.

Utilizando diversos elementos para a construção do Sítio do Picapau Amarelo, suas histórias não somente tinham o papel de entreter e divertir as crianças, como também de ensinar, instruir, educar.

Percebemos nos textos a intertextualidade quando nas histórias personagens de outros autores interagem com os personagens do Sítio, e até mesmo fogem de seus livros.

A referência a respeito do Barão de Munchausen deixa claro que tal qual em suas histórias os fatos nem sempre tem explicações lógicas, assim ocorre no Sítio, onde imaginação e realidade se misturam.

Teorias de aprendizagem de Jean Piaget e Vygotsky são notadas nos livros, onde temos a presença de personagens que servem de mediadores do conhecimento, e personagens que estão aprendendo através da maturação biológica e da interação social.

\section{REFERÊNCIAS}

BOSI, A. História concisa da literatura brasileira. São Paulo: Cultrix, 1994. 528p.

CADEMARTORI, Ligia. O que é literatura infantil. 2. ed. São Paulo: Brasiliense, 2010. CANDIDO, A. Formação da literatura brasileira. Belo horizonte: Itatiaia, 2006. 777p.

CARVALHO, Barbara Vasconcelos de. A Literatura Infantil - Visão Histórica e Crítica.

2. ed. São Paulo: Edart, 1983.

COELHO, Nelly Novaes. Literatura infantil: teoria, análise, didática. 7. ed. São Paulo: Ática, 2002.

COELHO, Nelly Novais. Panorama Histórico da Literatura Infantil Juvenil. 4.ed. São Paulo: Ática, 1991.

CUNHA, Maria Antonieta Antunes. Literatura Infantil - Teoria e Prática. 18. ed. São Paulo: Ática, 2003 
HEYWOOD, Colin. UMA HISTÓRIA DA INFÂNCIA: DA IDADE MÉDIA À ÉPOCA CONTEMPORÂNEA NO OCIDENTE. Porto Alegre: Artmed, 2004, 284p.

LAJOLO, Marisa; ZILBERMAN, Regina. Literatura Infantil Brasileira - História e Histórias. 6. ed. São Paulo: Ática, 2010.

LOBATO, Monteiro. Narizinho Arrebitado - São Paulo: Globinho, 2016. SARAIVA. ASSMANN, Juracy ; MÜGGE, Ernani. Literatura na escola: propostas para o ensino fundamental. Porto Alegre: Artmed, 2000.

LOBATO, Monteiro Narizinho Arrebitado [Livro]. - São Paulo : Globinho, 2016.

SARAIVA, Juracy Assmann; MÜGGE, Ernani. Literatura na escola: propostas para o ensino fundamental. Porto Alegre: Artmed, 2000.

PIAGET, Jean. A epistemologia genética. Petrópolis: Vozes, 1971.

SILVA, Vera Maria Tietzmann. Literatura infantil brasileira: um guia para professores e promotores de leitura. 2. Ed. Goiânia, GO.: Cânone Editorial, 2009.

ZILBERMAN, Regina; MAGALHÃES, Ligia Cademartori. Literatura Infantil: Autoritarismo e Emancipação. 3. ed. São Paulo: Ática, 1987.

ZILBERMAN, Regina. A literatura infantil na escola. 11. ed. São Paulo: Global, 2003.

Sites Consultados:

https://www.ebiografia.com/monteiro_lobato/

https://dicionariodoaurelio.com/literatura

https://charadasnoescuro.wordpress.com/2013/11/05/sitio-do-picapau-amarelo-e-a-

representacao-de-uma-identidade-cultural-na-nova-literatura-infantil-brasileira/

http://infantv.com.br/infantv/?p=13706

https://pedagogiaaopedaletra.com/comparando-teoria-piaget-vygotsky/ 